\title{
Specialist laboratory networks as preparedness and response tool - the Emerging Viral Diseases-Expert Laboratory Network and the Chikungunya outbreak, Thailand, 2019
}

Giulietta Venturi ${ }^{1}$, Stephan W Aberle ${ }^{2}$, Tatjana Avšič-Županc ${ }^{3}$, Luisa Barzon ${ }^{4}$, Christoph Batejat ${ }^{5}$, Elisa Burdino ${ }^{6}$, Fabrizio

Carletti $^{7}$, Rémi Charrel ${ }^{8}$, Iva Christova ${ }^{9}$, Jeff Connell ${ }^{10}$, Victor Max Corman ${ }^{11,12}$, Mary Emmanouil ${ }^{13}$, Anne J Jääskeläinen ${ }^{14}$, Ivan $K_{\text {Kurolt }}^{15}$, Yaniv Lustig ${ }^{16}$, Miguel J Martinez ${ }^{17}$, Marion Koopmans ${ }^{18}$, Orsolya Nagyy ${ }^{19}$, Trung Nguyen ${ }^{20}$, Anna Papa ${ }^{21}$, Mercedes Pérez-Ruiz ${ }^{22}$, Martin Pfeffer ${ }^{23}$, Jelena Protic ${ }^{24}$, Johan Reimerink ${ }^{25}$, Giada Rossini ${ }^{26}$, María Paz Sánchez-Seco Fariñas ${ }^{27}$, Jonas

Schmidt-Chanasit ${ }^{28}$, Sandra Söderholm ${ }^{29}$, Bertrand Sudre ${ }^{30}$, Marjan Van Esbroeck ${ }^{31}$, CHIKV-Working Group ${ }^{32}$, Chantal B

Reusken ${ }^{18,25}$

1. Department of Infectious Diseases, Istituto Superiore di Sanità, Rome, Italy

2. Center for Virology, Medical University of Vienna, Vienna, Austria

3. Institute of Microbiology and Immunology, Faculty of Medicine, Ljubljana, Slovenia

4. Department of Molecular Medicine, University of Padova, Padova, Italy

5. Laboratory for Urgent Response to Biological Threats (CIBU), Institut Pasteur, Paris, France

6. Laboratory of Microbiology and Virology, Amedeo di Savoia Hospital, Turin, Italy.

7. National Institute for Infectious Diseases 'Lazzaro Spallanzani' IRCCS, Rome, Italy

8. Unité des Virus Emergents (UVE: Aix Marseille Univ, IRD 190, INSERM 1207, IRBA, IHU Méditerranée Infection), Marseille, France

9. National Reference Vector-borne pathogens Laboratory, National Center of Infectious and Parasitic Diseases, Sofia, Bulgaria

10. National Virus Reference Laboratory, University College Dublin, Ireland

11. Department of Virology, Labor Berlin, Charité-Vivantes GmbH, Berlin, Germany

12. Charité-Universitätsmedizin Berlin, corporate member of Freie Universität Berlin, Humboldt-Universität zu Berlin, and Berlin Institute of Health, Institute of Virology, Berlin, Germany

13. Diagnostic Services Laboratory, Public Health Laboratories, Hellenic Pasteur Institute, Athens, Greece

14. Virology and Immunology, University of Helsinki and Helsinki University Hospital, Helsinki, Finland

15. Research unit, University Hospital for Infectious Diseases 'Dr. Fran Mihaljević', Zagreb, Croatia

16. Central Virology Laboratory, Ministry of Health, Chaim Sheba Medical Center, Tel-Hashomer, Israel

17. ISGlobal, Hospital Clínic - Universitat de Barcelona, Barcelona, Spain.

18. Department of Viroscience, Erasmus Medical Centre, Rotterdam, the Netherlands

19. Department of Virology, National Public Health Center, Budapest, Hungary

20. Département de Microbiologie, Laboratoire national de santé, Luxemburg

21. Department of Microbiology, Medical School, Aristotle University of Thessaloniki, Thessaloniki, Greece

22. Servicio de Microbiología, Hospital Universitario Virgen de las Nieves, Instituto de Investigación Biosanitaria, Granada, Spain

23. Institute of Animal Hygiene and Veterinary Public Health, Leipzig, Germany

24. National Reference Laboratory for ARBO viruses and haemorrhagic fever, Belgrade, Serbia

25. Centre for Infectious Disease Control, National Institute for Public Health and the Environment, Bilthoven, the Netherlands

26. Regional Reference Centre for Microbiological Emergencies (CRREM), Unit of Clinical Microbiology, St Orsola Malpighi Hospital, Bologna, Italy.

27. Centro Nacional de Microbiología. Instituto de Salud Carlos III, Madrid, España

28. WHO Collaborating Centre for Arbovirus and Haemorrhagic Fever Reference and Research, Bernhard Nocht Institute for Tropical Medicine, Hamburg, Germany

29. Department of Microbiology, The Public Health Agency of Sweden, Solna, Sweden

30. European Centre for Disease Prevention and Control, Solna, Sweden

31. Department of Clinical Sciences, Institute of Tropical Medicine, Antwerp, Belgium

32. The members of the CHIKV-Working Group are listed at the end of the article

Correspondence: Chantal B Reusken (Chantal.Reusken@RIVM.nl)

Citation style for this article:
Venturi Giulietta, Aberle Stephan W, Avšič-Županc Tatjana, Barzon Luisa, Batejat Christoph, Burdino Elisa, Carletti Fabrizio, Charrel Rémi, Christova Iva,

Venturi Giulietta, Aberle Stephan W, Avšič-Županc Tatjana, Barzon Luisa, Batejat Christoph, Burdino Elisa, Carletti Fabrizio, Charrel Rémi , Christova Iva,
Connell Jeff, Corman Victor Max, Emmanouil Mary, Jääskeläinen Anne J, Kurolt Ivan, Lustig Yaniv, Martinez Miguel J, Koopmans Marion , Nagy Orsolya, Nguyen

Connell Jeff, Corman Victor Max, Emmanouil Mary, Jääskeläinen Anne J, Kurolt Ivan, Lustig Yaniv, Martinez Miguel J, Koopmans Marion, Nagy Orsolya, Nguyen Trung, Papa Anna, Pérez-Ruiz Mercedes, Pfeffer Martin, Protic Jelena, Reimerink Johan, Rossini Giada, Sánchez-Seco Fariñas María Paz, Schmidt-Chanasit Jo
, Söderholm Sandra, Sudre Bertrand, Van Esbroeck Marjan, CHIKV-Working Group, Reusken Chantal B. Specialist laboratory networks as preparedness and response tool - the Emerging Viral Diseases-Expert Laboratory Network and the Chikungunya outbreak, Thailand, 2019. Euro Surveill. 2020;25(12):pii=1900438. https://doi.org/10.2807/1560-7917.ES.2020.25.12.1900438

Article submitted on 01 Jul 2019 / accepted on 01 Oct 2019 / published on 02 Apr 2020

We illustrate the potential for specialist laboratory networks to be used as preparedness and response tool through rapid collection and sharing of data. Here, the Emerging Viral Diseases-Expert Laboratory Network (EVD-LabNet) and a laboratory assessment of chikungunya virus (CHIKV) in returning European travellers related to an ongoing outbreak in Thailand was used for this purpose. EVD-LabNet rapidly collected data on laboratory requests, diagnosed CHIKV imported cases and sequences generated, and shared among its members and with the European Centre for Disease Prevention and Control. Data across the network showed an increase in CHIKV imported cases during 1 October 2018-30 April 2019 vs the same period in 2018 ( 172 vs 50), particularly an increase in cases known to be related to travel to Thailand ( 72 vs 1). Moreover, EVD-LabNet showed that strains were imported from Thailand that cluster with strains of 
the ECSA-IOL E1 A226 variant emerging in Pakistan in 2016 and involved in the 2017 outbreaks in Italy. CHIKV diagnostic requests increased by $23.6 \%$ between the two periods. The impact of using EVD-LabNet or similar networks as preparedness and response tool could be improved by standardisation of the collection, quality and mining of data in routine laboratory management systems.

\section{Background}

The rapid increase in chikungunya virus (CHIKV) cases in Thailand since October 2018 raised concerns in Europe about the potential increased risk for public health of CHIKV importation through returning travellers $[1,2]$. Thailand is a popular tourist destination with 6.5 million European travellers in 2017 alone [3]. In the last 3 months of 2018, Thailand reported 3,314 probable and confirmed cases and in 2019, as at 27 May $2019,3,592$ CHIKV cases were reported in 23 provinces [4]. Cases of CHIKV infection imported from Thailand into Europe and the Middle East were reported in early $2019[5,6]$.

Chikungunya is characterised by a rapid onset of high fever, rash and joint pain. CHIKV is an alphavirus that is transmitted to humans by the bite of some Aedes mosquitoes; Ae. albopictus, an important mosquito vector for CHIKV, is established in 15 European countries, mainly in the south of the continent [7]. Its presence has resulted in autochthonous transmission foci initiated by returning viraemic travellers in Italy and France on several occasions in the past [8-13]. It has been suggested that the A226V mutation in the $\mathrm{E}_{1}$ gene of the CHIKV genome could potentially influence the fitness of CHIKV East-Central-South African (ECSA)Indian Ocean lineage (IOL) strains for certain Ae. albopictus populations [14]. This variant caused the first European outbreak in Italy in 2007 [11] and several autochthonous infection foci in France in 2014 and $2017[8,9,12]$. However, in 2016 a sub-cluster of ECSAIOL strains without the A226V mutation emerged in Pakistan and neighbouring countries $[15,16]$. This E1 A226 variant caused two outbreaks with hundreds of cases in 2017 in Italy $[10,13]$ and experimental studies showed that the Pakistani variant was as efficiently transmitted by Italian Ae. albopictus mosquitoes as the E1 A226V 2007 outbreak strain $[17,18]$.

In southern Europe the Ae. albopictus activity season typically lasts between June and October. Its startheightens awareness regarding the risk of local CHIKV transmission following the introduction of the virus by travel-associated viraemic cases. Hence, questions arose in March 2019 with European public health authorities about the threat of the CHIKV outbreak in Thailand to Europe. An assessment of such threat would be informed by the number of diagnostic requests and imported cases as well as the CHIKV strain currently circulating in Thailand. Here, we illustrate the potential of specialist laboratory networks as preparedness and response tool by rapid collecting and sharing of data and laboratory-diagnosed CHIKV patients related to the outbreak in Thailand.

\section{Emerging Viral Diseases-Expert Laboratory Network}

International networking is essential for preparedness and response to emerging infectious disease events. Accurate laboratory diagnosis of emerging pathogens like CHIKV may be challenging, which can be problematic as it forms the basis for adequate surveillance, clinical and public health responses and monitoring of the effectiveness of prevention and intervention efforts [19]. These notions were recognised and in response, the European Centre for Disease Prevention and Control (ECDC) funded EVD-LabNet (https://www.evd-labnet. eu/). EVD-LabNet represents a laboratory and knowledge platform for support of clinical and public health preparedness and response through laboratory capacity and capability building. Moreover it provides access for ECDC, national public health authorities and its member laboratories to reference diagnostics, expertise and knowledge exchange [20,21]. EVD-LabNet comprises 61 expert laboratories in 30 European Union and European Economic Area (EU/EEA) countries, seven laboratories in seven EU pre-accession countries, three in two other European countries and six in six non-European countries. Among the EVDLabNet laboratories, 51 have the capacity to diagnose CHIKV infection by molecular tests and 44 by serological tests. Moreover, 22 and 29 laboratories have indicated to have the capability to isolate the virus and to characterise it through full genome sequencing and/or sequencing of PCR amplicons respectively. Sequence information is of importance for risk assessment and for the optimisation and evaluation of available diagnostic tests.

\section{Chikungunya cases imported from Thailand into Europe and Israel}

To substantiate the need for a heightened awareness for a possible increased public health risk of import of CHIKV cases from Thailand into Europe, we investigated whether the outbreak was reflected in the diagnostic requests and outcomes at EVD-LabNet member laboratories. Furthermore, we investigated whether genetic information, in particular about the $\mathrm{E}_{1}$ gene, on circulating strains was available. On 27 March 2019, the 51 EVD-LabNet laboratories that offer molecular CHIKV diagnostics were initially asked by email whether they had diagnosed any CHIKV cases related to the then ongoing outbreak in Thailand and if sequence information was (or could) become available.

In a follow up email on 2 May 2019, responding laboratories were asked for more details about the CHIKV diagnostic data collected between 1 October 2018 and 30 April 2019 relative to the same period from 2017 to 2018. In particular, laboratories were asked to share available information about CHIKV E1 sequences obtained from viraemic patients. These data are shown in Table 1 . They were used to further inform 
Chikungunya virus diagnostic requests and results, EVD-LabNet laboratories, 1 October 2017-30 April 2018 and 1 October 2018-30 April 2019

\begin{tabular}{|c|c|c|c|c|c|c|}
\hline \multirow[b]{3}{*}{$\begin{array}{l}\text { Reference Laboratories, country } \\
\text { (town) }\end{array}$} & \multirow{2}{*}{\multicolumn{2}{|c|}{$\begin{array}{c}1 \text { October } 2017-30 \text { April } 2018 \\
\text { Number of patients }\end{array}$}} & \multicolumn{4}{|c|}{1 October 2018-30 April 2019} \\
\hline & & & \multicolumn{2}{|c|}{ Number of patients } & \multirow{2}{*}{$\begin{array}{l}\text { Sequences from } \\
\text { CHIKV infected } \\
\text { patients related to } \\
\text { Thailand outbreak } \\
\text { (no., sequence) }\end{array}$} & \multirow{2}{*}{$\begin{array}{l}\text { If yes: } \\
\text { presence } \\
\text { of the E1 } \\
\text { A226V } \\
\text { mutation }\end{array}$} \\
\hline & $\begin{array}{l}\text { Positive for } \\
\text { CHIKV / total } \\
\text { tested }\end{array}$ & $\begin{array}{l}\text { Positive for CHIKV/ } \\
\text { total tested }{ }^{a} \text { known } \\
\text { to be from Thailand }\end{array}$ & $\begin{array}{l}\text { Positives/ } \\
\text { total } \\
\text { tested for } \\
\text { CHIKV }^{\mathrm{a}}\end{array}$ & $\begin{array}{l}\text { Positives/total } \\
\text { tested }{ }^{a} \text { known to } \\
\text { be from Thailand }\end{array}$ & & \\
\hline Austria (Vienna) & $1 / 199$ & $0 / 19$ & $9 / 266$ & $\begin{array}{c}8 / 26 \\
(5 \text { from Krabi, } 2 \\
\text { from Ko Samui, } 1 \\
\text { unknown) }\end{array}$ & $\begin{array}{l}\mathrm{Y}(5 \text { patients, } \mathrm{E} 1 \\
\text { partial sequence })\end{array}$ & $\mathrm{N}$ \\
\hline Belgium ( Antwerp) & $1 / 724$ & $0 / 22$ & $12 / 751$ & $4 / 30$ & $\mathrm{~N}$ & NA \\
\hline Bulgaria (Sofia) & $0 / 0$ & NA & $0 / 0$ & NA & NA & NA \\
\hline Croatia (Zagreb) & $0 / 1$ & $0 / 0$ & $0 / 1$ & $0 / 0$ & NA & NA \\
\hline Finland (Helsinki) & $1 / 101$ & $0 / 15$ & $10 / 64$ & $10 / 24$ & $\begin{array}{c}\mathrm{Y} \text { (2 patients, full } \\
\text { genome) }\end{array}$ & $\mathrm{N}$ \\
\hline France (Marseille) & $0 / 240$ & o/unknown & $10 / 1236$ & $1 / 42$ & $\mathrm{~N}$ & NA \\
\hline France (Paris) & $0 / 0$ & NA & $0 / 0$ & 0 & $\mathrm{~N}$ & NA \\
\hline Germany (Berlin) & $2 / 43$ & Unknown & $0 / 17$ & o/unknown & NA & NA \\
\hline Germany (Hamburg) & $18 / 1,283$ & Unknown & $51 / 1263$ & 1/unknown & $\mathrm{N}$ & NA \\
\hline Germany (Leipzig) & $0 / 0$ & NA & $0 / 0$ & NA & NA & NA \\
\hline Greece (Thessaloniki) & $0 / 2$ & $0 / 0$ & $0 / 0$ & NA & NA & NA \\
\hline Greece (Athens) & $0 / 3$ & $0 / 0$ & $0 / 2$ & $0 / 0$ & NA & NA \\
\hline Hungary (Budapest) & $2 / 146$ & $0 / 32$ & $2 / 120$ & $0 / 29$ & NA & NA \\
\hline Ireland (Dublin) & $0 / 45$ & Unknown & $2 / 48$ & 1/unknown & $\mathrm{N}$ & NA \\
\hline Italy (Bologna) & $2 / 107$ & $0 / 4$ & $4 / 75$ & $4 / 7$ & $\begin{array}{c}\mathrm{Y}(1 \text { patient, E1 } \\
\text { partial sequence })\end{array}$ & N \\
\hline Italy (Rome, INMI) & $0 / 170^{b}$ & $0 / 15$ & $2 / 135$ & $1 / 12$ & $\begin{array}{c}\mathrm{Y}(1 \text { patient, } \mathrm{E} 1 \\
\text { partial sequence })\end{array}$ & $\mathrm{N}$ \\
\hline Italy (Rome, ISS) & $1 / 42^{\mathrm{b}}$ & $0 / 2$ & $3 / 39$ & $1 / 5$ & $\mathrm{~N}$ & NA \\
\hline Italy-(Padua) & $2 / 165$ & $0 / 8$ & $3 / 137$ & $1 / 16$ & $\mathrm{~N}$ & NA \\
\hline Italy (Turin) & $0 / 43$ & $0 / 3$ & $1 / 46$ & $1 / 7$ & $\mathrm{~N}$ & NA \\
\hline Luxembourg (Luxembourg) & $0 / 81$ & $0 / 4$ & $0 / 92$ & $0 / 9$ & NA & NA \\
\hline Serbia (Belgrade) & $1 / 1$ & $0 / 0$ & $0 / 0$ & $0 / 0$ & NA & NA \\
\hline Slovenia (Ljubljana) & $1 / 20$ & Unknown & $1 / 26$ & $1 / 1$ & $\begin{array}{l}\text { Y (1 patient, full } \\
\text { genome) }\end{array}$ & $\mathrm{N}$ \\
\hline Spain (Barcelona) & $\begin{array}{c}0 / 273 \\
2^{c}\end{array}$ & o/unknown & $\begin{array}{c}0 / 287 \\
1^{c} \\
\end{array}$ & $\begin{array}{c}\text { o/unknown } \\
1^{c} \\
\end{array}$ & $\begin{array}{l}\text { Y (1 patient }{ }^{c}, E_{1} \\
\text { partial sequence })\end{array}$ & N \\
\hline Spain (Granada) & $2 / 43$ & $1 / 13$ & $0 / 31$ & $0 / 5$ & NA & NA \\
\hline Spain (Madrid) & $8 / 375$ & $0 / 6$ & $2 / 492$ & $0 / 8$ & NA & NA \\
\hline Sweden (Solna) & $3 / 94$ & o/unknown & $48 / 514$ & 32/unknown & $\mathrm{N}$ & NA \\
\hline The Netherlands (Bilthoven) & $1 / 237$ & $0 / 6$ & $2 / 218$ & $1 / 8$ & $\mathrm{~N}$ & NA \\
\hline The Netherlands (Rotterdam) & $1 / 175$ & $0 / 3$ & $5 / 218$ & $4 / 13$ & $\mathrm{~N}$ & NA \\
\hline Israel (Tel Aviv) & $3 / 85$ & Unknown & $6 / 75$ & 1/unknown & $\begin{array}{c}\mathrm{Y}(1 \text { patient, } \mathrm{E} 1 \\
\text { partial sequence })\end{array}$ & N \\
\hline Total & $50 / 4,698$ & $1 / 152$ & $173 / 6,153$ & $72 / 242$ & & \\
\hline
\end{tabular}

CHIKV: chikungunya virus; EVD-LabNet: Emerging Viral Diseases-Expert Laboratory Network; N: no; NA: not applicable; Y: yes.

a Includes molecular and/or serology requests.

${ }^{b}$ Only travellers from endemic regions different from Italy in 2017.

'Cases diagnosed in September (outside the period of study). 
TABLE 2

Overview of chikungunya virus sequence data provided by EVD-LabNet, 2019

\begin{tabular}{|c|c|c|c|c|}
\hline Reference Laboratories & $\begin{array}{c}\text { GeneBank accession } \\
\text { number }\end{array}$ & $\begin{array}{c}\text { 5'-3' ends of sequenced } \\
\text { amplicon }\end{array}$ & $\begin{array}{c}\text { Sample Collection } \\
\text { Date }\end{array}$ & $\begin{array}{l}\text { Site of Origin of the } \\
\text { imported case (if known) }\end{array}$ \\
\hline Austria, Vienna.AUT/02.2019 & MN053046 & $10211-10917$ & 7 February 2019 & Unknown \\
\hline Austria, Vienna.AUT/09.2019 & MNo53047 & $10194-10932$ & 25 February 2019 & Thailand-Krabi \\
\hline Austria, Vienna.AUT/09.2019/2 & MNo53048 & $10194-10985$ & 25 February 2019 & Thailand-Krabi \\
\hline Austria, Vienna.AUT/12.2019 & MNo53049 & $10194-10899$ & 21 March 2019 & Thailand-Krabi \\
\hline Austria, Vienna.AUT/12.2019/2 & MN053050 & $10194-10881$ & 21 March 2019 & Thailand-Krabi \\
\hline Finland, Helsinki-1 & MNo75149 & Full genome & 25 February 2019 & Thailand-Phuket \\
\hline Finland, Helsinki-2 & MN075150 & Full genome & 27 February 2019 & Thailand-Phuket \\
\hline Italy (Bologna) & MNo47314 & 9994-11312 & 2 March 2019 & Unknown \\
\hline Italy (Rome, INMI) & MK986662 & $10180-10922$ & 4 February 2019 & Unknown \\
\hline Israel (Tel Aviv) & MK992771 & $10525-11170$ & 17 February 2019 & Unknown \\
\hline Slovenia (Ljubljana) & MK848202 & Full genome & $\begin{array}{l}21 \text { November } \\
2018\end{array}$ & Unknown \\
\hline Spain (Barcelona) & MNo80498 & $10254-10712$ & $\begin{array}{l}6 \text { September } \\
2018\end{array}$ & Unknown \\
\hline
\end{tabular}

EVD-LabNet: Emerging Viral Diseases-Expert Laboratory Network.

a Reference sequence for determination of 5'-3' ends of sequenced amplicons: CHIKV S27 - ECSA Africa prototype, GeneBank accession number: AF369024.

the assessment of risk of local transmission by $A e$. albopictus.

Within 2 days, 39 laboratories (representing 21 EU/EEA countries, two EU pre-accession countries, two other European countries and one non-European country) responded to the initial request indicating whether or not they had diagnosed CHIKV cases and obtained associated sequences related to the increased numbers of CHIKV cases reported in Thailand. Of 39 respondents, 17 (in 12 EU/EEA, one other European and one non-European country) indicated to have diagnosed CHIKV cases related to the outbreak in Thailand. Of 39 respondents, 29 laboratories in 18 countries (17 EU/EEA and one non-European) answered to the more detailed second request for information; three laboratories (in three EU/EEA countries) had no CHIKV requests in either of the specified time periods.

Between 1 October 2018 and 30 April 2019, 6,153 patients were tested by 26 laboratories for CHIKV of which $173(2.8 \%)$ were indicated to be probable and confirmed cases of CHIKV infection based on national case definitions. Among 242 patients with known travel history to Thailand, $72(29.8 \%)$ were diagnosed as probable and confirmed CHIKV cases. A $23.6 \%$ increase in the total number of patients tested for CHIKV (regardless of travel destination) was observed for the period from 1 October to 30 April in 2018 vs 2019.

During the same period in 2018, 4,698 patients were tested for CHIKV infection of which, 50 (1.1\%) were identified as probable and confirmed CHIKV cases; only one probable case was known to be acquired in Thailand. One laboratory in Spain diagnosed two CHIKV cases in September 2017 and one in September
2018. As the latter case was a traveller returning from Thailand, sequence information related to this case was included in this study.

\section{Phylogenetic analysis}

During the study period, CHIKV sequences were available for 12 patients, linked to travel to Thailand, in seven laboratories in six countries: nine partial E1 sequences and three full genome sequences. None of the sequences carried the E1-A226V mutation. The partial sequences analysed of the Thailand strains are listed in Table 2.

Phylogenetic analysis was performed based on E1 partial region 10194-11170 (reference strain CHIKV S27, GenBank AF369024) that was the minimal overlap in all sequences provided. As shown in the Figure, the partial E1 sequences of the strains imported from Thailand clustered together with the CHIKV ECSA-IOL strain that emerged around 2004 resulting in widespread outbreaks. Particularly, they clustered in the sub-group comprising sequences of the recently emerged ECSAIOL variant ('Pakistan ECSA-IOL' variant group, Figure) involved in the 2017 epidemic in Pakistan [15] and Italy $[10,17,22]$. All European ex-Thailand sequences were highly similar, with nt differences ranging between o and $0.006 \%$ in the $976 \mathrm{bp}$ overlapping fragment that was analysed.

\section{Discussion}

In response to the Thailand-CHIKV alert, EVD-LabNet was able to rapidly inventory and share among its members and with ECDC, data on laboratory-diagnosed imported CHIKV cases and sequences. This information directly enhanced risk assessment at ECDC by informing experts during the daily round table meeting where 


\section{FIGURE}

Neighbour-joining phylogenetic analysis of partial E1 region sequences derived from chikungunya virus-positive cases imported from Thailand into Europe, October 2018-April 2019
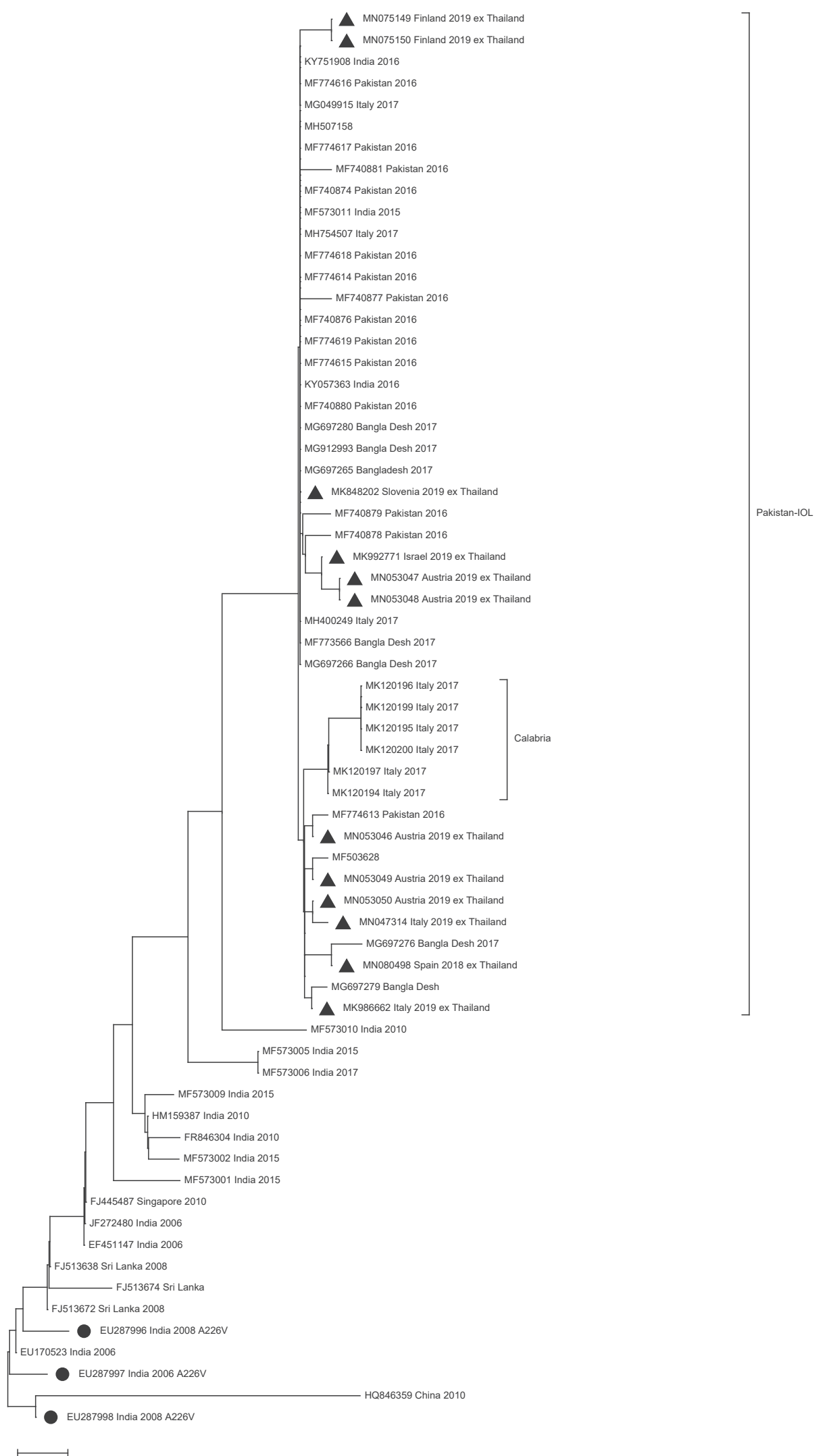

0.0010

ECSA-IOL sequences available from the European Nt Archive (ENA) data bank were included in the analysis. Phylogenetic analysis was performed on E1 partial region 10194-11170 (reference strain CHIKV S27, GenBank AF369024) that was the minimal overlap in all sequences provided. Gaps in the alignment due to differences in the length of sequenced amplicons were ignored in the distance model. The phylogenetic tree was constructed using Tamura-Nei model with 1,000 bootstrap reiterations. Two major clusters are highlighted in the Figure: one cluster comprising the ex-Thailand sequences reported here and a second cluster, which includes sequences with the A226V mutation in the envelope E1 gene (indicated with a black circle). The scale bar indicates the percentage of diversity. The branch length of 0.001 was chosen to better show the relatedness of ex-Thai sequences. For each sequence in the tree, GenBank accession number/country of origin of the infection/year of the infection are reported. Sequences characterised in this study are indicated by a black triangle. 
active communicable disease threats are reviewed. While CHIKV is classified as a notifiable disease in the EU [23], reporting of pathogens like CHIKV to ECDC through the European surveillance system (TESSy) does not happen on a real-time basis with regard to returning travellers. TESSy data are usually reported in annual epidemiological reports with surveillance atlas data typically published ca 1 year late [24]. Furthermore, regular surveillance systems do mostly not collect data on the total numbers of diagnostic requests that laboratories have received. Such information is, however, relevant for an adequate assessment of the general level of preparedness and awareness among physicians and current pressure on laboratory response through increased diagnostic requests.

The exchange of snapshot laboratory data within a network such as EVD-LabNet has the advantage of a timely provision of essential data and opens the possibility to direct further investigations, for example through phylogenetic characterisation targeting the presence of virulence and/or vector competence markers and validating common diagnostic tests. However, most laboratories processing vast amounts of diagnostic requests indicated that their routine laboratory information management systems are not set up to enable easy extraction of answers to such queries, and some epidemiological parameters, like travel destination, are often not provided. Furthermore, a lack of standardisation across Europe of e.g. protocols (including specific tests used and interpretation), clinical and laboratory case definitions and local situation-driven differences in test requesting behaviour of clinicians will bias data collection. Hence, the potential impact of international laboratory networks as preparedness and response tool can be further enhanced by improvement and standardisation of collection, quality and mining of data.

Nevertheless, we observed a $23.6 \%$ increase in CHIKV diagnostic requests across the participating laboratories during the study period. Moreover, we observed an increase in the number of positive laboratory cases, and in particular an increase of CHIKV-infected travellers from Thailand. The place of infection was unknown for many diagnostic requests and confirmed cases, making it likely that the number of requests and cases associated with travel to Thailand might be under reported in this study and highlighting the importance of a complete travel anamnesis not only for diagnostic and clinical purposes but for epidemiological analysis as well [25]. The E1-A266V mutation was not present in the partial CHIKV sequences generated from 12 of 73 imported cases from Thailand (including the Spanish case from September 2018), but the phylogenetic analysis revealed a high similarity with the strain involved in a large outbreak in the Indian sub-continent and the Ae. albopictus-sustained outbreak that occurred in Italy in 2017. Based on information from previous CHIKV outbreaks in Thailand, an E1 A226V strain was expected to cause the 2018-2019 outbreak in Thailand
$[26,27]$. The circulation of E1 A226 CHIKV in Thailand highlights the interconnectivity in Asia and the occurrence of outbreak strain replacement in endemic areas.

\section{Conclusion}

The rapid data collection within EVD-LabNet showed that an increased awareness existed among physicians of the possibility of travellers returning from Thailand with an acute CHIKV infection. The timely sharing of the data within the network and with ECDC alerted the network that a further increase in diagnostic requests could be expected while it stressed the need for awareness that with the start of the vector activity season in Europe and the simultaneous upcoming peak in vector activity in the rainy season in Thailand (JuneOctober) increasing numbers of returning viraemic travellers could have been the source for autochthonous CHIKV transmission in areas with competent vector species while the outbreak in Thailand was ongoing. International laboratory strengthening networks like EVD-LabNet have the opportunity to rapidly collect a European overview of imported laboratory cases and associated critical sequence information, and thus have the potential to inform risk assessments of the public health sector with directly relevant information thereby filling an important role in strengthening preparedness and response.

\section{CHIKV Working Group}

Claudio Argentini, Christopher Barbara, Concetta Castilletti, Pascal Cherpillod, Christian Drosten, Niklas Edner, Philip Eisermann, Olivier Engler, Sandra Essbauer, Claudia Fortuna, Guillaume Fournier, Paolo Gaibani, Valeria Ghisetti, Roger Hewson, Lyudmila Karan, Gulay Korukluoglu, Miša Korva, Isabelle Leparc-Goffart, Giulia Marsili, Aleksander Michalski, Maria Grazia Milia, Richard Molenkamp, Jessica Navero-Castillejos, Laetitia Ninove,Irene Pedrosa-Corral, Maria Carla Re, Sara Sanbonmatsu-Gámez,Teemu Smura, Jelena Storozenko, Olli Vapalahti, Caterina Vocale, Alexander Zoufaly

\section{Acknowledgements}

EVD-LabNet is supported by the European Centre for Disease Prevention and Control (ECDC) under the EVD-LabNet Framework contract ECDC/2016/002. We are grateful to Katrin Leitmeyer and Tamas Bakonyi at ECDC for network support.

\section{Conflict of interest}

None declared.

Authors' contributions

GV: data collection, co-write manuscript.

SWA, TAZ, LB, CB, EB, FC, RC, IC, JC, VMC, ME, AJJ, IK, YL, MJM, MK, ON, TN, AP, MPR, MP, JP, JR, GR, MPSSF, JSC, SS, BS, MVE: provision of extensive data Table 1 and 2, comments on manuscript. 
CBR: data collection, co-write manuscript, network coordination.

CHIKV-working group: data provision and/or comments on manuscript.

\section{References}

1. European Centre for Disease Prevention and Control (ECDC). Communicable disease threats report, 23-29 September 2018, week 39. Stockholm: ECDC; 28 Sep 2018. Available from: https://ecdc.europa.eu/en/publications-data/communicabledisease-threats-report-23-29-september-2018-week-39

2. European Centre for Disease Prevention and Control (ECDC). Communicable Disease Threats Report, 20-26 January 2019, week 4. Stockholm: ECDC; 25 Jan 2019. Available from: https:// ecdc.europa.eu/en/publications-data/communicable-diseasethreats-report-20-26-january-2019-week-4

3. World Tourism Organization (UNWTO). Thailand: Countryspecific: Basic indicators (Compendium) 2013 - 2017 (12.2018). Madrid: UNWTO; Dec 2018. Available from: https://www.eunwto.org/doi/pdf/10.5555/unwtotfb0764010020132017201812

4. European Centre for Disease Prevention and Control (ECDC). Communicable Disease Threats Report, 19-25 May 2019, Week 21. Stockholm: ECDC; 24 May 2019. Available from: https://ecdc.europa.eu/en/publications-data/ communicable-disease-threats-report-19-25-may-2019-week-21

5. Javelle E, Florescu SA, Asgeirsson H, Jmor S, Eperon G, Leshem $\mathrm{E}$, et al. Increased risk of chikungunya infection in travellers to Thailand during ongoing outbreak in tourist areas: cases imported to Europe and the Middle East, early 2019. Euro Surveill. 2019;24(10). https://doi.org/10.2807/1560-7917. ES.2019.24.10.1900146 PMID: 30862335

6. Kantele A. Travellers as sentinels of chikungunya epidemics: a family cluster among Finnish travellers to Koh Lanta, Thailand, January 2019. Euro Surveill. 2019;24(11). https:// doi.org/10.2807/1560-7917.ES.2019.24.11.1900162 PMID: 30892179

7. European Centre for Disease Prevention and Control (ECDC). Aedes albopictus - current known distribution: January 2019. Stockholm: ECDC; 30 Jan 2019. Available from: https://ecdc.europa.eu/en/publications-data/ aedes-albopictus-current-known-distribution-january-2019

8. Calba C, Guerbois-Galla M, Franke F, Jeannin C, Auzet-Caillaud M, Grard G, et al. Preliminary report of an autochthonous chikungunya outbreak in France, July to September 2017. Euro Surveill. 2017;22(39). https://doi.org/10.2807/1560-7917. ES.2017.22.39.17-00647 PMID: 29019313

9. Delisle E, Rousseau C, Broche B, Leparc-Goffart I, L'Ambert G, Cochet $A$, et al. Chikungunya outbreak in Montpellier, France, September to October 2014. Euro Surveill. 2015;20(17):21108. https://doi.org/10.2807/1560-7917.ES2015.20.17.21108 PMID: 25955774

10. Venturi G, Di Luca M, Fortuna C, Remoli ME, Riccardo F, Severini $F$, et al. Detection of a chikungunya outbreak in Central Italy, August to September 2017. Euro Surveill. 2017;22(39). https://doi.org/10.2807/1560-7917. ES.2017.22.39.17-00646 PMID: 29019306

11. Rezza G, Nicoletti L, Angelini R, Romi R, Finarelli AC, Panning $M$, et al. CHIKV study group. Infection with chikungunya virus in Italy: an outbreak in a temperate region. Lancet. 2007;370(9602):1840-6. https://doi.org/10.1016/S01406736(07)61779-6 PMID: 18061059

12. Grandadam $M$, Caro V, Plumet $S$, Thiberge JM, Souarès $Y$, Failloux $A B$, et al. Chikungunya virus, southeastern France. Emerg Infect Dis. 2011;17(5):910-3. https://doi.org/10.3201/ eid1705.101873 PMID: 21529410

13. Vairo F, Mammone A, Lanini S, Nicastri E, Castilletti C, Carletti $F$, et al. Local transmission of chikungunya in Rome and the Lazio region, Italy. PLoS One. 2018;13(12):e0208896. https:// doi.org/10.1371/journal.pone.0208896 PMID: 30576334

14. Tsetsarkin KA, Vanlandingham DL, McGee CE, Higgs S. A single mutation in chikungunya virus affects vector specificity and epidemic potential. PLoS Pathog. 2007;3(12):e201. https://doi. org/10.1371/journal.ppat.0030201 PMID: 18069894

15. Mallhi TH, Khan YH, Khan AH, Tanveer N, Qadir MI. First chikungunya outbreak in Pakistan: a trail of viral attacks. New Microbes New Infect. 2017;19:13-4. https://doi.org/10.1016/j. nmni.2017.05.008 PMID: 28663798

16. Melan A, Aung MS, Khanam F, Paul SK, Riaz BK, Tahmina $\mathrm{S}$, et al. Molecular characterization of chikungunya virus causing the 2017 outbreak in Dhaka, Bangladesh. New Microbes New Infect. 2018;24:14-6. https://doi.org/10.1016/j. nmni.2018.03.007 PMID: 29707212
17. Lindh E, Argentini C, Remoli ME, Fortuna C, Faggioni G, Benedetti E, et al. The Italian 2017 Outbreak Chikungunya Virus Belongs to an Emerging Aedes albopictus-Adapted Virus Cluster Introduced From the Indian Subcontinent. Open Forum Infect Dis. 2018;6(1):ofy321. PMID: 30697571

18. Fortuna C, Toma L, Remoli ME, Amendola A, Severini F, Boccolini D, et al. Vector competence of Aedes albopictus for the Indian Ocean lineage (IOL) chikungunya viruses of the 2007 and 2017 outbreaks in Italy: a comparison between strains with and without the E1:A226V mutation. Euro Surveill. 2018;23(22). https://doi.org/10.2807/1560-7917.ES.2018.23.22.1800246 PMID: 29871722

19. Reusken CB, leven M, Sigfrid L, Eckerle I, Koopmans M. Laboratory preparedness and response with a focus on arboviruses in Europe. Clin Microbiol Infect. 2018;24(3):221-8. https://doi.org/10.1016/j.cmi.2017.12.010 PMID: 29274465

20. Charrel R, Mögling R, Pas S, Papa A, Baronti C, Koopmans M, et al. Variable Sensitivity in Molecular Detection of Zika Virus in European Expert Laboratories: External Quality Assessment, November 2016. J Clin Microbiol. 2017;55(11):3219-26. https:// doi.org/10.1128/JCM.00987-17 PMID: 28835479

21. Jacobsen S, Patel P, Schmidt-Chanasit J, Leparc-Goffart I, Teichmann A, Zeller $\mathrm{H}$, et al. External quality assessment studies for laboratory performance of molecular and serological diagnosis of Chikungunya virus infection. J Clin Virol. 2016;76:55-65. https://doi.org/10.1016/j.jcv.2016.01.008 PMID: 26828561

22. Carletti F, Marsella P, Colavita F, Meschi S, Lalle E, Bordi L, et al. Full-Length Genome Sequence of a Chikungunya Virus Isolate from the 2017 Autochthonous Outbreak, Lazio Region, Italy. Genome Announc. 2017;5(49):e01306-17. https://doi. org/10.1128/genomeA.01306-17 PMID: 29217791

23. European Commission. Commission Implementing Decision (EU) $2018 / 945$ of 22 June 2018 on the communicable diseases and related special health issues to be covered by epidemiological surveillance as well as relevant case definitions (Text with EEA relevance). Official Journal of the European Union. Luxembourg: Publications Office of the European Union 6.7.2018:L 170/1. Available from: https://eur-lex.europa.eu/legal-content/EN/ TXT/?uri=CELEX\%3A32018Do945

24. European Centre for Disease Prevention and Control (ECDC). Chikungunya virus disease - Annual Epidemiological Report for 2017. Stockholm: ECDC; 3 Apr 2019; Available from: https://ecdc.europa.eu/en/publications-data/ chikungunya-virus-disease-annual-epidemiological-report-2017

25. Cleton N, Reusken C, Murk JL, de Jong M, Reimerink J, van der Eijk A, et al. Using routine diagnostic data as a method of surveillance of arboviral infection in travellers: a comparative analysis with a focus on dengue. Travel Med Infect Dis. 2014;12(2):159-66. https://doi.org/10.1016/j. tmaid.2013.10.015 PMID: 24291263

26. Sasayama M, Benjathummarak S, Kawashita N, Rukmanee $P$, Sangmukdanun $S$, Masrinoul $P$, et al. Chikungunya virus was isolated in Thailand, 2010. Virus Genes. 2014;49(3):485-9. https://doi.org/10.1007/s11262-014-1105-5 PMID: 25113745

27. Wanlapakorn N, Thongmee T, Linsuwanon P, Chattakul P, Vongpunsawad S, Payungporn S, et al. Chikungunya outbreak in Bueng Kan Province, Thailand, 2013. Emerg Infect Dis. 2014;20(8):1404-6. https://doi.org/10.3201/eid2008.140481 PMID: 25061989

\section{License, supplementary material and copyright}

This is an open-access article distributed under the terms of the Creative Commons Attribution (CC BY 4.0) Licence. You may share and adapt the material, but must give appropriate credit to the source, provide a link to the licence and indicate if changes were made.

Any supplementary material referenced in the article can be found in the online version.

This article is copyright of the authors or their affiliated institutions, 2020. 